\title{
Rare intracranial EWSR1-rearranged myxoid mesenchymal tumour in a teenager
}

\author{
Jason W Adams, ${ }^{1}$ Denise Malicki, ${ }^{2}$ Michael Levy, ${ }^{3}$ John Ross Crawford ${ }^{4}$
}

${ }^{1}$ Neurosciences, University of California San Diego, La Jolla, California, USA

${ }^{2}$ Pathology, Rady Children's Hospital University of California San Diego, San Diego,

California, USA

${ }^{3}$ Neurosurgery, University of California San Diego, San Diego, California, USA

${ }^{4}$ Neurosciences and Pediatrics, University of California San Diego, La Jolla, California, USA

Correspondence to Dr John Ross Crawford; jrcrawford@ucsd.edu

Accepted 20 July 2021

Check for updates

(C) BMJ Publishing Group Limited 2021. No commercial re-use. See rights and permissions. Published by BMJ.

To cite: Adams JW,
Malicki D, Levy M, et al. BMJ
Case Rep 2021;14:e245282.
doi:10.1136/bcr-2021-
245282

\section{DESCRIPTION}

A 14-year-old girl presented with 10 months of worsening headaches with associated nausea and 1 month of visual impairment, including blurry and double vision. Her headaches initially occurred monthly but increased in frequency and became intractable to medical management. Physical examination was significant for papilloedema on funduscopic examination and a right inferior quadrantanopia but was negative for other neurological abnormalities. MRI revealed a peripherally located, homogeneously hyperenhancing mass in the left posterior supratentorial compartment that was T1-hypointense and T2-hyperintense with slight heterogeneity (figure 1). Cortical vasculature displacement indicated extra-axial location. No dural tail or calcifications were appreciated, but hyperintensity of the white matter involving the left parietal lobe and compression of the left occipital lobe. The neuroradiographic differential diagnoses included meningioma, atypical haemangiopericytoma, lymphoma and gliosarcoma. The patient underwent surgical resection where neuropathology revealed spindle cell proliferation of low cellularity with angulate, hyperchromatic nuclei and thin strands of cytoplasm separated by an abundant myxoid background (figure 2). Sparsely scattered rosette-like structures with a central core of densely eosinophilic, hypocellular collagenous material were detected. Little mitotic activity was observed, and reticulin staining revealed abundant network deposition around the tumour cells. The histological differential diagnoses for myxoid soft tissues include myxoma, myxoid liposarcoma, myxoid chondrosarcoma, low-grade fibromyxoid sarcoma and myxoid undifferentiated pleomorphic sarcoma (myxofibrosarcoma). Immunohistochemistry showed diffuse and strongly positive staining for CD99 and slight epithelial membrane antigen and desmin positivity. Few $(<1 \%) \mathrm{Ki}-67+$ nuclei were noted, and a subset of tumour nuclei stained positive for beta-catenin. Scattered CD68 + cells throughout the lesion were noted. Immunostaining was negative for S100, SMA, synaptophysin, GFAP, CD34, STAT-6, NF, myogenin and ALK-1. Features customarily observed in angiomatoid fibrous histiocytosis (AFH) - fibrous pseudocapsule, lymphoplasmacytic infiltrates and blood-filled cystic spaces were not appreciated. Next-generation sequencing detected a variant of unknown significance in TOP2A (c97A $>$ C) but no known clinically significant variants. Microarray likewise detected no clinically significant abnormalities. Fluorescence in situ hybridisation demonstrated rearrangement of the

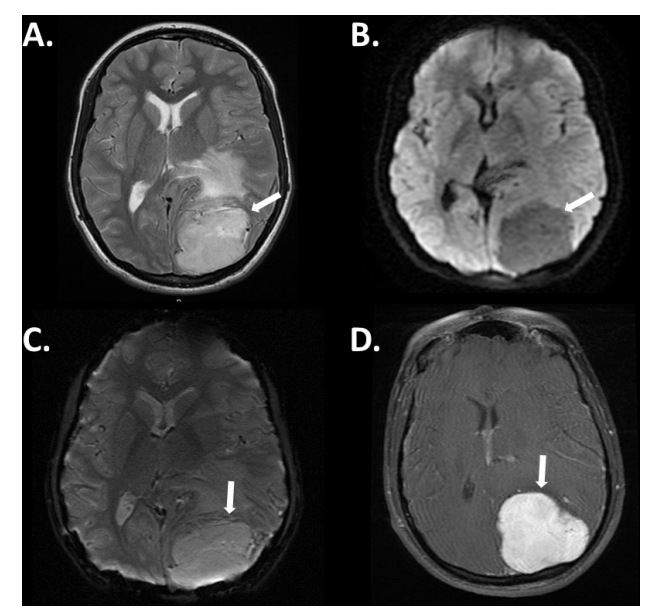

Figure 1 Neuroimaging features of central nervous system mixed mesenchymal tumour. MRI reveals a large left posterior tumour with surrounding vasogenic oedema on T2-weighted sequences (A), with no evidence of reduced diffusivity (B) or susceptibility-weighted artefact (C) that shows homogeneous enhancement on T1-post gadolinium weighted sequences (D).

EWSR1 gene at 22q12. These findings were most consistent with a diagnosis of EWSR1-rearranged myxoid mesenchymal tumour. The patient underwent complete tumour resection and has been

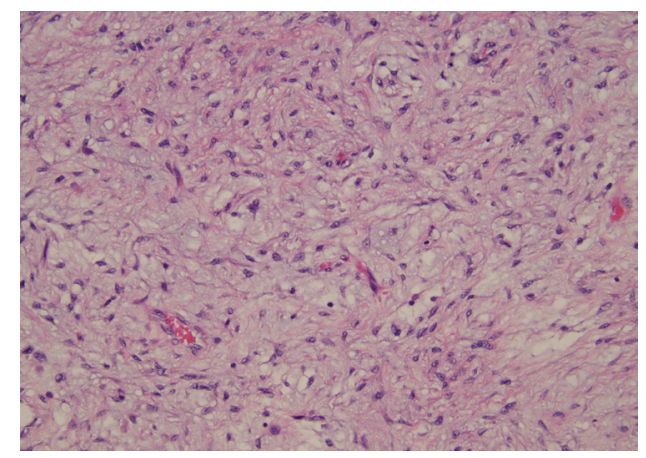

Figure 2 Neuropathology of central nervous system mixed mesenchymal tumour. H\&E stained section reveals a spindle cell proliferation of low cellularity with angulate, hyperchromatic nuclei and thin strands of cytoplasm separated by an abundant myxoid background. Scattered 'rosette-like' structures with a central core of densely eosinophilic, hypocellular collagenous material. Mitotic activity is inconspicuous. Reticulin stain showed abundant background deposition around tumour cells and diffuse positivity for CD99 (not shown) consistent with a diagnosis of mixed mesenchymal tumour. 
recurrence free 3 years post-resection with resolution of right inferior quandrantanopia.

Genetic rearrangement featuring EWSR1 fusion can occur in a diverse array of mesenchymal neoplasms. ${ }^{1}$ However, EWSR1rearrangement mesenchymal tumours in the central nervous system are exceedingly rare and were unreported until recently, with the presentation of a small case series of adolescents and young adults with intracranial myxoid mesenchymal tumours positive for EWSR1 rearrangement. ${ }^{2}$ Subsequent literature has sought to determine whether these tumours are a novel neoplastic entity or represent a myxoid variant of $\mathrm{AFH},{ }^{3}$ but emerging case reports and a recent effort to summarise this spectrum of neoplasms have revealed considerable variability in their histology and clinical course, ${ }^{2-11}$ complicating this effort. Further case descriptions are necessary to refine our understanding of these tumours. We add to the current literature the case of a 14-year-old girl with a rare intracranial, EWSR1-rearranged myxoid mesenchymal tumour.

\section{Learning points}

- Intracranial EWSR1-rearranged myxoid mesenchymal tumour (IMMT) is a rare neoplasm thought to occur most frequently in adolescents and young adults.

- Whether IMMT is a novel neoplastic entity or represents an intracranial myxoid variant of angiomatoid fibrous histiocytoma is yet undetermined.

- IMMT should be considered with the support of histology and genetic analyses within broad radiological and histological differential diagnoses, including meningioma, atypical haemangiopericytoma, lymphoma, gliosarcoma, myoepithelial tumours, myxoma, myxoid liposarcoma and myxoid chondrosarcoma.
Contributors JWA, DM, ML and JRC were responsible for the design and creation of the case report.

Funding The authors have not declared a specific grant for this research from any funding agency in the public, commercial or not-for-profit sectors.

Competing interests None declared.

Patient consent for publication Obtained.

Provenance and peer review Not commissioned; externally peer reviewed.

\section{REFERENCES}

1 Romeo S, Dei Tos AP. Soft tissue tumors associated with EWSR1 translocation. Virchows Arch 2010;456:219-34.

2 Kao Y-C, Sung Y-S, Zhang L, et al. Ewsr 1 fusions with CREB family transcription factors define a novel myxoid mesenchymal tumor with predilection for intracranial location. Am J Surg Pathol 2017;41:482-90.

3 Bale TA, Oviedo A, Kozakewich H, et al. Intracranial myxoid mesenchymal tumors with EWSR1-CREB family gene fusions: myxoid variant of angiomatoid fibrous histiocytoma or novel entity? Brain Pathol 2018;28:183-91.

4 Libbrecht S, Van Der Meulen J, Mondelaers V, et al. Intracranial myxoid mesenchymal tumor with EWSR1-CREB1 fusion. Pathol Res Pract 2020;216:153239.

5 Komatsu M, Yoshida A, Tanaka K, et al. Intracranial myxoid mesenchymal tumor with EWSR1-CREB1 gene fusion: a case report and literature review. Brain Tumor Pathol 2020;37:76-80.

6 White MD, McDowell MM, Pearce TM, et al. Intracranial myxoid mesenchymal tumor with rare EWSR1-CREM translocation. Pediatr Neurosurg 2019;54:347-53.

7 Valente Aguiar P, Pinheiro J, Lima J, et al. Myxoid mesenchymal intraventricular brain tumour with EWSR1-CREB1 gene fusion in an adult woman. Virchows Arch 2021;478:1019-24.

8 De Los Santos Y, Shin D, Malnik S, et al. Intracranial myxoid mesenchymal neoplasms with EWSR 1 gene rearrangement: report of 2 midline cases with one demonstrating durable response to MET inhibitor monotherapy. Neurooncol Adv 2021;3:1-5.

9 Ballester LY, Meis JM, Lazar AJ, et al. Intracranial myxoid mesenchymal tumor with EWSR1-ATF1 fusion. J Neuropathol Exp Neurol 2020;79:347-51.

10 Konstantinidis A, Cheesman E, O'Sullivan J, et al. Intracranial Angiomatoid fibrous histiocytoma with EWSR1-CREB family fusions: a report of 2 pediatric cases. World Neurosurg 2019;126:113-9

11 Sloan EA, Chiang J, Villanueva-Meyer JE. Intracranial mesenchymal tumor with FET-CREB fusion-A unifying diagnosis for the spectrum of intracranial myxoid mesenchymal tumors and angiomatoid fibrous histiocytoma-like neoplasms. Brain Pathol 2020;31:e12918:1-21.

Copyright 2021 BMJ Publishing Group. All rights reserved. For permission to reuse any of this content visit

https://www.bmj.com/company/products-services/rights-and-licensing/permissions/

BMJ Case Report Fellows may re-use this article for personal use and teaching without any further permission.

Become a Fellow of BMJ Case Reports today and you can:

- Submit as many cases as you like

- Enjoy fast sympathetic peer review and rapid publication of accepted articles

- Access all the published articles

Re-use any of the published material for personal use and teaching without further permission

Customer Service

If you have any further queries about your subscription, please contact our customer services team on +44 (0) 2071111105 or via email at support@bmj.com.

Visit casereports.bmj.com for more articles like this and to become a Fellow 